\title{
Cryptococcus gattii: An Emerging Cause of Fungal Disease in North America
}

\author{
Ashwin Dixit, ${ }^{1,2}$ Scott F. Carroll, ${ }^{1,3}$ and Salman T. Qureshi ${ }^{1,4}$ \\ ${ }^{1}$ Centre for the Study of Host Resistance, McGill University, Montreal, QC, Canada H3G 1A4 \\ ${ }^{2}$ Department of Microbiology and Immunology, McGill University, Montreal, QC, Canada H3A 2B4 \\ ${ }^{3}$ Department of Human Genetics, McGill University, Montreal, QC, Canada H3A 1B1 \\ ${ }^{4}$ Department of Medicine, McGill University, Montreal, QC, Canada H3G 1A4
}

Correspondence should be addressed to Salman T. Qureshi, salman.qureshi@mcgill.ca

Received 11 November 2008; Accepted 18 January 2009

Recommended by Bettina Fries

During the latter half of the twentieth century, fungal pathogens such as Cryptococcus neoformans were increasingly recognized as a significant threat to the health of immune compromised populations throughout the world. Until recently, the closely related species C. gattii was considered to be a low-level endemic pathogen that was confined to tropical regions such as Australia. Since 1999, C. gattii has emerged in the Pacific Northwest region of North America and has been responsible for a large disease epidemic among generally healthy individuals. The changing epidemiology of $C$. gattii infection is likely to be a consequence of alterations in fungal ecology and biology and illustrates its potential to cause serious human disease. This review summarizes selected biological and clinical aspects of $C$. gattii that are particularly relevant to the recent North American outbreak and compares these to the Australian and South American experience.

Copyright (C) 2009 Ashwin Dixit et al. This is an open access article distributed under the Creative Commons Attribution License, which permits unrestricted use, distribution, and reproduction in any medium, provided the original work is properly cited.

\section{Introduction}

Although less than 500 of the estimated 1.5 million species of fungi pose a threat to humans and animals [1, 2], the prevalence of fungal infections has risen over the last century due to a progressive increase in the number of debilitated individuals. Impaired immunity against fungi may result from one or more factors including malignancy, advanced or severe comorbid disease, or the use of cytotoxic drugs and broad-spectrum antibiotics. Species of Candida remain the most common cause of invasive yeast infection; however, opportunistic filamentous fungi such as Aspergillus spp, Fusarium spp, Scedosporium spp, Penicillium spp, and the zygomycota are becoming more prevalent in oncology and transplant centers $[3,4]$. Human disease resulting from environmental exposure to the basidiomycetous yeast Cryptococcus neoformans increased significantly since the onset of the HIV epidemic and continues to be common among individuals that do not have access to effective antiretroviral therapy $[5,6]$. C. gattii, a closely related species that was traditionally associated with tropical and subtropical climates, is now gaining prominence as a cause of human and veterinary disease in North America. While most clinical cases have occurred among generally healthy individuals that reside in the Pacific Northwest, a few tourists or visitors to the region have also been affected. The purpose of this review is to summarize important biological and clinical characteristics of $C$. gattii that are relevant to the understanding of human disease caused by this emerging fungal pathogen.

\section{Identification}

C. neoformans was first isolated in 1894 from fermented peach juice by the Italian Francesco Sanfelice [7]. Since that time, this organism has been recovered from numerous locations throughout the world where its main ecological niche is soil, particularly in association with pigeon excreta [8-10]. Cryptococci grow as unicellular, encapsulated cells in the asexual state or as basidiomycetous filaments in the sexual state $[1,11]$. Infection due to this opportunistic fungus is believed to occur by inhalation and primarily 
targets the lung with frequent dissemination to the central nervous system as well as a variety of other organs $[12,13]$.

C. gattii was first isolated from a leukemic patient in 1970 and described as a variant of C. neoformans [14]. C. gattii is closely related to $C$. neoformans, although its distribution is not global. C. gattii is typically restricted to tropical and subtropical geographical regions such as Australia, Brazil, and southern California $[15,16]$. In the laboratory, these two cryptococcal species can be distinguished on the basis of their capsular serotype: C. gattii belongs to serotypes B and C, while C. neoformans belongs to serotypes A and D [17]. Like C. neoformans, C. gattii typically causes pneumonia and meningitis [15]. However, C. gattii appears to have a greater propensity to infect immune competent humans $[18,19]$.

For reasons that are not yet fully understood, C. gattii has acquired the ability to colonize new biogeoclimatic regions and is responsible for a recent outbreak of infection among humans and animals in the temperate climate of Vancouver Island, British Columbia (BC), Canada [20]. Between 1999 and 2006, 171 human cases of $C$. gattii infection were identified, including 8 fatalities [21]. Between 2002 and 2005, the incidence of $C$. gattii infection on Vancouver Island peaked at 36 cases/million people/year, a number that was significantly higher than the 0.94 cases/million people/year observed in endemic regions of Australia [22, 23]. The most common clinical manifestation of C. gattii infection on Vancouver Island was pneumonia [21]. Although the majority of human infections have been found on the east coast of Vancouver Island [23], clinical cases have also been reported on the $\mathrm{BC}$ mainland, Alberta, and the states of Oregon and Washington [22, 24, 25]. Given the ongoing spread of C. gattii infection on the Pacific coast of North America, it will be important for clinicians and laboratory scientists to remain vigilant for diseases that may be caused by this fungal pathogen.

\section{Taxonomy}

Cryptococcus is a largely polyphyletic genus that consists of at least 37 different species and belongs to the kingdom Fungi, phylum Basidiomycota, class Tremellomycetes, and order Tremellales [26-28]. The subclassification of this genus has been the subject of much debate and modification, particularly in response to the development of newer molecular typing methods $[26,27,29]$. The $C$. neoformans species complex was first classified according to structural variations of the extracellular polysaccharide capsule that are distinguished by agglutination assays with antigen-specific antibodies [30, 31]. Using this approach, C. neoformans was classified into four serotypes, A through D, in the 1950s and 1960 s $[30,32]$. The hybrid serotype AD is often considered to be a fifth serotype of the $C$. neoformans species complex, and rare hybrid serotypes between C. neoformans and C. gattii such as BD and AB have also been observed [33-37].

C. gattii was initially classified as a variety of $C$. neoformans, bearing the name C. neoformans var. gattii or var. bacillispora $[15,38]$. Subsequently, C. gattii and C. neoformans were shown to have substantial differences in their biochemistry, ecology, epidemiology, and clinical manifestations (see review [15]) as a result of the divergence of serotypes A and D from serotypes B and C that occurred approximately 37 million years ago [15, 39]. Following a series of revisions to the classification of the $C$. neoformans species complex $[11,14,17,38,40,41]$, cryptococci are now divided into two major species, C. neoformans (serotypes A, $\mathrm{D}$, and $\mathrm{AD}$ ) and C. gattii (serotypes B and C). The sexual state of C. gattii is known as Filobasidiella bacillispora [38, 41].

The most recent classification of cryptococci was established by genetic typing using PCR fingerprinting, random amplification of polymorphic DNA (RAPD), amplified fragment length polymorphism (AFLP) analysis and multilocus sequence typing (MLST) [17, 23, 35, 37, 42-45]. Based on genetic diversity, cryptococci were divided into eight molecular types associated with distinct AFLP profiles. $C$. neoformans may be classified into VNI/VNII genotypes corresponding to AFLP1/1A/1B (serotype A), VNIII/AFLP3 (serotype $\mathrm{AD}$ ), and VNIV/AFLP2 (serotype D), while $C$. gattii may be distinguished as VGI/AFLP4 (serotype B), VGII/AFLP6 (serotype B), VGIII/AFLP5 (serotype B or C), and VGIV/AFLP7 (serotype B or C). Interspecific hybrid serotypes $\mathrm{BD}$ and $\mathrm{AB}$ correspond to AFLP8 and AFLP9, respectively $[35,37]$. The VNI and VGI genotypes are the most prevalent isolates of each species. The Vancouver $C$. gattii isolates have a VGII genotype that is further subtyped into VGIIa (major) and VGIIb (minor) [23]. A recent study employing MLST of one hundred and seventeen isolates confirmed previous observations that four monophyletic lineages exist within C. gattii. Based on these findings, it was suggested that these lineages should be considered as separate taxa, similar to the two monophyletic lineages within C. neoformans that correspond to varieties grubii and neoformans [45]. Another MLST study has indicated that although the Vancouver Island C. gattii strains have colonized a novel environment, they are not phylogenetically unique [46].

\section{Ecology and Epidemiology of C. gattii}

C. gattii is endemic in tropical and subtropical regions such as Australia where it is most commonly associated with eucalyptus trees, particularly Eucalyptus camaldulensis and Eucalyptus tereticornis [15, 47-49]. The fungus has also been found to grow on other tree species such as almond (Prunus dulcis), golden shower (Cassia fistula), and Douglas fir (Pseudotsuga menziesii) in Colombia, Brazil, and Vancouver Island, respectively [17, 47]. C. gattii has also been isolated from insect frass in Australia and a wasp nest in Uruguay $[50,51]$. Other species in the Filobasidiella lineage, such as Cryptococcus amylolentus, Tsuchiyaea wingfieldii, and Bullera dendrophila, have also been isolated from insect frass [5254]. In this context, the recent discovery of C. gattii in the Pacific Northwest is intriguing, since this temperate climate is characterized by mild and wet winters and warm and dry summers. On Vancouver Island, C. gattii has mainly been found on trees in the coastal Douglas fir (CDF) biogeoclimatic zone such as fir, cedar, and maple [23, 47]. 
The fungus has also been isolated from the air, freshwater, seawater, and upper layer of the soil of the $\mathrm{BC}$ mainland, the Gulf Islands, and Washington state [22, 23, 47].

Ecological and geographical differences exist among the different molecular types of $C$. gattii. A survey conducted in 16 countries revealed that the molecular types most commonly found in the clinic and environment were VGI and VGII [55]. Genotype VGIII has been found in the United States, Mexico, South America, Europe, India, Australia, and New Zealand, while VGIV has been isolated in Mexico, Colombia, Europe, South Africa, and India [44, 55-58]. A recent epidemiological survey across Europe showed that $C$. gattii clinical infection is rare in this continent, represented by only six of 535 serotyped Cryptococcus isolates [59]. In this study, the genotypes of the six European C. gattii isolates identified were not determined. In Australia, the C. gattii VGI genotype is the most common clinical or environmental isolate, while the VGII genotype is an infrequent cause of human or animal infection $[15,50]$. A notable exception to this overall pattern is the Northern Territory of Australia that does not contain eucalyptus trees yet has the highest incidence of clinical C. gattii infection. Interestingly, most human cases in this region are due to VGII, suggesting that $C$. gattii has colonized a new environmental niche [60,61]. This possibility is also supported by the fact that eucalyptus trees in the rest of Australia have only yielded the VGI genotype [62].

While the majority of C. gattii isolates in Australia's Northern Territory and on Vancouver Island are of the VGII genotype, a notable difference between the two regions is the remarkably limited diversity of the latter. Specifically, ninety five percent of the environmental and clinical samples on Vancouver Island are of the VGII genotype, and within this group $90 \%$ are of the major genotype VGIIa [47]. MLST studies have shown that the Vancouver Island VGIIa genotype is identical to two known C. gattii strains: the 1975 Seattle human isolate NIH 444 (also known as CBS 6956 and ATCC 32609) and the 1992 San Francisco environmental isolate CBS 7750 isolated from E. camaldulensis [63]. These studies have also demonstrated that the VGIIa isolates from Vancouver Island, the BC mainland, the Gulf Islands and northern Washington State are genetically identical [22]. These findings indicate that the major genotype VGIIa has existed in the Pacific Northwest for more than 30 years and it is hypothesized that VGIIa originated from sexual mating between VGIIb and another unknown parental strain [63]. Notably, VGI and VGII clinical isolates from Oregon differed from the Vancouver Island VGI and VGII samples at one or more of the loci that were analyzed [22]. The reason for this is not clear but may be explained by divergent evolution from a common genotype or the presence of distinct genetic isolates residing in the Pacific Northwest. The VGIIb minor genotype on Vancouver Island is identical to the unusually fertile Australian VGIIb clinical isolate NT-13, suggesting that the Vancouver Island isolate originated in Australia [63]. The VGI genotype is rarely found on Vancouver Island and it remains unclear whether it has actually colonized the environment, and the molecular types VGIII and VGIV have not yet been reported $[23,46]$. Recent studies on C. gattii clinical and environmental isolates from South America have shown that VGII predominates over the other molecular types in both Colombia and Brazil as observed on Vancouver Island $[47,64,65]$. Meyer et al. have hypothesized that the Vancouver Island outbreak isolates originated in South America based on the finding of $\alpha$ mating-type cells within the Brazilian C. gattii VGII population and the fact that all Vancouver Island C. gattii isolates found to date have also been of the $\alpha$ mating type $[63,65,66]$. In addition, the VGII genotype has been present in Brazil longer than it has been on Vancouver Island [65]. In contrast, C. gattii VGII isolates (serotype B) in Colombia are mainly of the opposite a mating type, although large numbers are present in regions that have a temperate climate that is similar to Vancouver Island [64].

\section{Virulence Factors}

C. gattii and C. neoformans share many attributes that increase their ability to invade and survive in a host organism [92]. The main virulence factors identified in C. gattii to date include an outer polysaccharide capsule, melanin, mannitol, extracellular proteinase, products of the laccase pathway, superoxide dismutase, phospholipases, urease, and the STE12 $\alpha$ transcription factor (a homologue of Saccharomyces cerevisiae STE12) that is present only in the $\alpha$ mating type (Table 1) [93]. Other properties of $C$. gattii contribute to its infectivity such as its ability to grow at physiological temperature [15], its tolerance of low $\mathrm{pH}$ and elevated salt levels [47], and its ability to switch capsular phenotype [91].

A carbohydrate-rich outer capsule that is composed primarily of glucuronoxylomannan (GXM) with smaller proportions of galactoxylomannan (GalXM) and mannoproteins is the major virulence factor for both C. gattii and C. neoformans [94]. The capsule may change in composition and size through a process called phenotypic switching (described further in the Notable Attributes section) and induces suppression of the host immune response by various mechanisms including the downregulation of cytokine and chemokine expression in dendritic cells (Table 1) [91, 95]. Kinetic studies have shown that complement component C3 binds less efficiently to C. gattii compared to C. neoformans, suggesting that $C$. gattii enhances virulence by preferential evasion of immune recognition [96]. Speciesspecific variation in the expression of other virulence factors may also play a role in their pattern of infectivity and organ dissemination. For instance, it was observed that extracellular proteinase production is lower in certain strains of $C$. gattii compared to a number of $C$. neoformans isolates, suggesting that $C$. gattii may less efficiently degrade proteins involved in tissue integrity and host immunity such as collagen, fibrin, complement, and immunoglobulin [7982]. This finding may explain why C. gattii lesions are often more circumscribed compared to C. neoformans, a characteristic that could also reduce local and systemic dissemination $[82,97]$. Similarly, in vitro experiments with a variety of C. neoformans and C. gattii isolates from 
TABLe 1: C. gattii virulence factors and their functions.

\begin{tabular}{|c|c|}
\hline Factor & Function \\
\hline \multirow{6}{*}{ Capsule and its associated polysaccharides } & Evasion of phagocytosis [67] \\
\hline & Reduction of antigen presentation [68] \\
\hline & Reduction of cytokine production [69] \\
\hline & $\begin{array}{l}\text { Induction of suppressor T-cells which inhibit cell-mediated } \\
\text { immunity [70] }\end{array}$ \\
\hline & Inhibition of T-cell responses by GXM [31] \\
\hline & $\begin{array}{l}\text { Inhibition of leukocyte migration into inflammatory sites by GXM } \\
{[31,71]}\end{array}$ \\
\hline \multirow{4}{*}{ Melanin } & Protection against UV radiation [72] \\
\hline & Protection against oxygen and nitrogen free radicals $[73,74]$ \\
\hline & May contribute to central nervous system tropism [6] \\
\hline & Contributes to negative cellular charge [75] \\
\hline \multirow{3}{*}{ Mannitol } & Suggested increase in intracranial pressure [76] \\
\hline & Protection against stress [77] \\
\hline & Protection against oxygen free radicals [78] \\
\hline \multirow{2}{*}{ Extracellular protease } & Proteolytic activity [79] \\
\hline & $\begin{array}{l}\text { May contribute to degradation of proteins involved in tissue } \\
\text { integrity and host immunity [79-82] }\end{array}$ \\
\hline \multirow{3}{*}{ Products of laccase pathway } & Diphenol oxidation [83] \\
\hline & Synthesis of melanin [84] \\
\hline & Degradation of wood lignin [15] \\
\hline \multirow{2}{*}{ Superoxide dismutase } & Protection against oxidative stress [85] \\
\hline & $\begin{array}{l}\text { Protection against oxidative burst produced by immune effector } \\
\text { cells [85] }\end{array}$ \\
\hline Phospholipases & $\begin{array}{l}\text { Tissue invasion via degradation of mammalian membrane lipids } \\
\text { and lung surfactant }[15,86]\end{array}$ \\
\hline \multirow{2}{*}{ Urease } & Exact function is unknown [87] \\
\hline & May aid in transfer of Cryptococcus to central nervous system [88] \\
\hline STE $1 \alpha$ transcription factor (in cells of $\alpha$ mating type) & $\begin{array}{l}\text { Upregulation leads to synthesis of diphenol oxidase (which is a } \\
\text { laccase) }[89,90]\end{array}$ \\
\hline Growth at physiological temperature $\left(37^{\circ} \mathrm{C}\right)$ & Survival and persistence in the host [15] \\
\hline Tolerance of low $\mathrm{pH}$ & Survival and persistence in the environment [47] \\
\hline Tolerance of elevated salt & Survival and persistence in the environment [47] \\
\hline Phenotypic switching & $\begin{array}{l}\text { Change in capsule size-mucoid variant more virulent, smooth } \\
\text { variant suggested to be able to cross blood-brain barrier [91] }\end{array}$ \\
\hline
\end{tabular}

South America have shown that C. neoformans has increased urease production relative to $C$. gattii [98]. Intratracheal administration of the highly virulent C. neoformans H99 (serotype A) to mice suggests that urease may aid in the dissemination of the fungus from the lung to the central nervous system, although the exact mechanism is unknown [88]. It is also interesting to note that virulence factors are involved not only in pathogenesis but also in commensalism. For instance, C. gattii was observed to share an endophytic relationship with decaying wood of both eucalypt and noneucalypt trees, where the laccase enzyme system appears to play a role in digestion of lignin [15, 50].

Given that C. neoformans and C. gattii appear to share many of the same virulence factors, it is intriguing that
C. gattii most commonly infects immune competent individuals while $C$. neoformans primarily infects the immune compromised host. One explanation for this observation is that immune compromised individuals simply have more environmental exposure to $C$. neoformans compared to $C$. gattii [5]. Furthermore, the contribution of host genetic background to resistance against cryptococcal infection is even less well understood. Interestingly, certain groups of individuals such as the Australian aboriginal population may be predisposed to C. gattii disease [62]. Modern molecular dissection of a microorganism's virulence factors may allow researchers to better understand the genetic mechanisms underlying virulence. A recent example of this approach used systematic targeted gene deletion in C. neoformans with comprehensive profiling of individual mutants in an animal 
model [99]. A similar large-scale strategy may be required to clearly delineate the pathogenesis of C. gattii and may in turn stimulate the development of novel therapeutic strategies.

\section{Notable Attributes of $C$. gattii}

Phenotypic switching and same-sex mating are two interesting attributes that contribute to the virulence of $C$. gattii. The term phenotypic switching refers to an adaptive mechanism characterized by structural modifications of the extracellular capsule and cell wall [91]. This phenomenon occurs infrequently in vitro or during chronic infection and a switch to a more mucoid form is associated with greater virulence in C. neoformans $[91,100]$. Reversible phenotypic switching between a smooth and mucoid variant of C. gattii strain NP1 has also been identified [100]. Shortly after infection, the mucoid form of NP1 is most commonly observed; however, a subsequent switch to the smooth form characterized by reduced capsular polysaccharide allows for easier penetration of the blood-brain barrier and dissemination to the brain [91]. Evaluation of survival and fungal burden in $\mathrm{BALB} / \mathrm{c}$ mice following intravenous or intratracheal infection with either $C$. gattii NP1 phenotypic variant demonstrated increased virulence of the mucoid form. In this study, both mucoid and smooth variants were found in the lung homogenates while only the smooth variant was found in the brain homogenates. In terms of the immune response, infection with the smooth variant elicited a greater inflammatory response as characterized by lymphocyte and monocyte infiltration and gave rise to smaller cryptococcomas than the mucoid variant [91].

In contrast to most Australian C. gattii isolates, it was demonstrated that all Vancouver Island isolates belong to the $\alpha$ mating-type and are unusually fertile $[63,66]$. The mechanism by which cryptococcal cells of an identical mating type replicate is not known. However, it has been suggested that $C$. gattii undergoes same-sex mating, a process that has been studied in C. neoformans [63]. Upon nutrient limitation, $\alpha$ haploid cells can undergo sexual recombination via fruiting, a process by which haploid cells fuse, chromosomal reassortment and recombination occur, followed by meiosis and sporulation $[66,101]$. Same-sex mating between two $\alpha$ cells (rather than an $\alpha$ and an a cell) may confer a survival advantage and could explain why all Vancouver isolates are of the $\alpha$ mating type [101]. Both traditional and same-sex mating in C. neoformans have been observed in the laboratory but not in nature $[63,66,101,102]$.

\section{Animal Models of $\boldsymbol{C}$. gattii Infection}

A limited number of animal model studies of C. gattii infection have been reported in literature. One group has investigated the survival of $\mathrm{A} / \mathrm{J}$ inbred mice following intranasal infection with different Vancouver Island C. gattii molecular types. In this report, the major genotype VGIIa appeared most virulent (20\% survival at 15 days postinfection), the minor genotype VGIIb was avirulent (100\% survival at 55 days post-infection), and the VGI genotype was similar in virulence to VGIIa [63]. These findings are consistent with recent clinical experience that has shown VGIIa to be the most common isolate from patients $[21,22$, $24,103]$.

Further insights into disease pathogenesis have been derived through animal studies using C. gattii isolates that were not obtained from Vancouver Island. One study compared mouse and human pulmonary inflammatory responses to intratracheal infection with 10 different Australian isolates of C. gattii [104]. In BALB/c mice, 6 isolates did not elicit any inflammatory response, 3 provoked a minimal response, and 1 resulted in a strong host inflammatory response that took several weeks to develop. The peak inflammatory response was observed 5 weeks after infection and was characterized by foamy macrophages, lymphocytes, poorly defined granulomas containing some giant cells as well as C. gattii yeast, and destruction of lung tissue. In humans, variable pulmonary pathology has been detected including poorly formed granulomas containing intracellular C. gattii, lymphocytic interstitial pneumonitis, tissue necrosis, and fibrosis. In both species the local lymphocyte pool consisted largely of T-cells with a 2:1 ratio of CD4 to CD8 cells in humans [104].

A second study examined the pathology seen in BALB/c mice following systemic infection with the clinical isolate C. gattii 9714 (CBS 6996, serotype B, VGIII/AFLP5) under different experimental conditions $[105,106]$. It was observed that both immune competent and hydrocortisone-treated mice developed $C$. gattii disease, contrasting with the apparent predilection of immune competent humans to this infection. At high doses of C. gattii, immune suppressed mice were more likely to develop severe disease compared to immune competent mice. SCID mice that lack T- and Blymphocytes were more susceptible to infection relative to wild-type BALB/c, suggesting a protective role for these cell types [105]. Comparative studies showed that C. neoformans 9759 (a serotype A clinical isolate) has increased virulence compared to C. gattii 9714 after systemic infection of $\mathrm{BALB} / \mathrm{c}$ mice, regardless of the immune state of the animal. Specifically, C. neoformans 9759 infected the brain and lungs of BALB/c mice, while C. gattii 9714 affected the lungs and skin. Ulcerative lesions on the tail due to intravenous $C$. gattii infection were more common in immune competent mice, while rectal prolapse was more common in immune suppressed mice. This study also demonstrated that infection by either C. neoformans 9759 or C. gattii 9714 may cause gastrointestinal pathology, although its incidence was rare [105].

A third study examined the pathogenesis of five Cryptococcus isolates administered to BALB/c mice via the intraperitoneal route [107]. The isolates included C. gattii GR52 and GR56 (both serotype B), from immune competent goats that died of pneumonia in Spain; C. gattii B4506 (serotype B), an Australian environmental isolate known to be highly pathogenic in mice; C. gattii I-682 (serotype C), from a Colombian native almond tree; and C. neoformans GR297 (serotype D), from an AIDS patient in Spain with meningitis. Two of five mice infected with $C$. neoformans GR297 developed liver and peritoneal abscesses and one 
mouse died after four weeks. Fungal cultures of spleen, liver, kidney, testes, lung, and brain were done for each group and were positive in at least one organ for GR52, GR297, GR56, B4506, and I-682 in 80\%, 77\%, 70\%, 70\%, and $33 \%$ of the cases, respectively [107]. Based on the frequency of cryptococcal growth in the organ cultures, all fungal isolates with the exception of the serotype $C$ sample I-682 displayed similar virulence in BALB/c mice. Among the organs tested, the spleen was most often positive for Cryptococcus (91\%), followed by the liver (75\%), kidney (75\%), testes (71\%), lung (62\%), and brain (29\%). C. gattii GR52, the cause of a pneumonia outbreak in goats, was also isolated from the lungs of all $\mathrm{BALB} / \mathrm{c}$ mice studied, suggesting that it has a particular tropism for lung tissue. Pathologic findings associated with infection of the brain included areas of spongiosis in the white matter with an abundance of encapsulated yeasts in the basal ganglia while infected lungs showed encapsulated yeasts within alveoli, peribronchial vessels, and interalveolar spaces. Interestingly, inflammation was not observed in either organ among infected mice [107].

These studies show that the route of experimental cryptococcal infection is a major determinant of the site of disease. In general, intravenous infection directly induces systemic disease, whereas inhalation of the fungus via the airway mimics the natural route of infection and leads to primary disease in the lung [108]. For example, in the second study both the cutaneous and gastrointestinal pathologies may have been a direct result of C. gattii administration through the tail vein, and significant involvement of the visceral organs and peritoneum in the third animal study may have resulted from intraperitoneal inoculation of the fungus. Nonetheless, the tissue tropism observed in humans is similar to that seen in these mouse models $[13,15,21]$. In addition to the route of infection, these studies also confirm that other variables such as the C. gattii isolate, infectious dose, and immune status of the host also play a role in the virulence of the fungus and the severity of infection [15].

\section{Veterinary Cases}

C. gattii has the potential to infect a wide range of animals throughout the world, including wild, farm, domestic, and aquatic animals, along with a variety of birds. This broad host range was observed during the recent outbreak in British Columbia [23, 109, 110]. In order to study the epidemiology of veterinary cases, diagnostic methods to test for infection in animals generally consist of serum and/or tissue sampling and nasal swabbing [28, 109, 111-113]. A recent study examined the characteristics of C. gattii infection in domestic animals in southwestern BC, involving 78 feline and 51 canine cases [28]. It was observed that cats were 4.4 times more likely than dogs to be positive for C. gattii infection, and that all cases in dogs and $50 \%$ of cases in cats were due to $C$. gattii serotype B [111]. In cats, the median age at diagnosis was 7.3 years, whereas in dogs it was 2.3 years [28]. The tissue tropism of C. gattii disease differs slightly in cats and dogs. Among canines, the affected organs included the respiratory system (52\%), central nervous system (42\%), and the skin or gastrointestinal tract $(6 \%)$, while in felines $56 \%$ were respiratory, 26\% involved the central nervous system, and $19 \%$ were dermal with no cases of gastrointestinal involvement [28].

Another study was carried out on Vancouver Island to determine whether wild animals were infected with $C$. gattii. Of the 91 animals that underwent swabbing of the nasal cavity, two eastern grey squirrels were found to be positive for C. gattii. This number is similar to the incidence of infection in asymptomatic companion animals; specifically $1.1 \%$ of dogs, $4.3 \%$ of cats and $1.5 \%$ of horses were positive for $C$. gattii [109]. Subclinical C. gattii infection in dogs and cats does not necessarily progress to clinical disease. In some cases it may be cleared while in other cases it may persist or develop into more severe disease [115]. It has also been suggested that infected wild animals may be an important vector for the spread of $C$. gattii from Vancouver Island to geographic regions that do not harbor the organism and that veterinary cases may also be a reliable sentinel of human disease [109]. The latter assertion is based on the observation that $C$. gattii infection was identified in animals prior to the human outbreak that began on Vancouver Island in 1999 and that nearly twice as many animals appeared to be infected with C. gattii compared to humans between 1999 and 2003 [116]. These observations also highlight a potential role for animals in transmission of infection to humans. While zoonotic transmission of $C$. gattii has not been reported to date, transmission of $C$. neoformans from pet birds to humans has been documented, and possible human-tohuman transmission has also been described [117-119]. In addition to the veterinary cases in the Pacific Northwest, outbreaks of C. gattii involving goats in Spain [120] and psittacine birds in Brazil [112] have also been observed.

\section{Human C. gattii Infection}

C. gattii may cause mild to severe clinical disease in the apparently healthy as well as immune compromised host. Like other cryptococcal species, C. gattii enters the human host through the inhalation of airborne propagules and targets the lung as a primary site of infection $[22,108]$. In some cases dissemination via the bloodstream may occur, most commonly to the central nervous system (CNS) with occasional spread to other organs such as skin, eye, and prostate $[13,15,82]$. The predominant manifestations of $C$. gattii infection involve the lungs in the tropical climate of Australia (66\% pulmonary) as well as the temperate climate of Vancouver Island and its surroundings (75\% pulmonary) $[21,60]$.

A study performed by the British Columbia (BC) Cryptococcal Working Group at the University of British Columbia reviewed the clinical aspects of 171 individual human cases of C. gattii infection on Vancouver Island from 1999 to 2006 [21]. It was determined that the mean age at diagnosis was 59 years, with a range of 2 to 92 years. Males (56\%) appeared to be slightly more susceptible to infection than females (44\%) [21]. The clinical patterns of C. gattii infection were 
pulmonary (75\%), neurological (8\%), combined (9\%), and unknown (8\%). Of those patients with combined disease, the main sites involved the lung and CNS, and less commonly the skin and lung, or skin and CNS. Death was a rare outcome of C. gattii infection on Vancouver Island with 8 fatalities from 1999 to 2006, or approximately one death per year. Of the deceased patients, five presented with both pulmonary and CNS pathology, three had other underlying comorbidities, and one had an adverse reaction to therapy. The mean age of the deceased patients was 61 years (range from 26 to 87) [21].

A summary of the most recent case reports associated with the Pacific west coast is presented in Table 2. Among the first 8 patients, three patients resided in British Columbia, two patients resided in Oregon State, one resided in Washington state, one resided in Alberta, and one patient was a tourist from Denmark visiting Vancouver Island [22, 24, $25,103]$. The place of residence of patients 9 to 12 was not specified, although they represented patients discharged from Vancouver Island hospitals [114]. Six of the cases were either not directly exposed to C. gattii on Vancouver Island or were exposed many years earlier. This suggests that another source of C. gattii may exist outside of Vancouver Island, or that the fungus may have been transiently present in other geographic regions due to dispersal mechanisms [22, 121]. Also, the fact that in two cases infected individuals had traveled to Vancouver Island 4 and 14 years before developing symptoms raises the possibility that $C$. gattii may remain latent in the body and reactivate at a later time [5].

In the BC Cryptococcal Working Group study, the pulmonary symptoms most commonly observed in the 171 cases were cough and dyspnea, while the main symptom involving the CNS was headache [21]. Similarly, the usual symptoms in the Pacific west coast case reports were cough and shortness of breath, although some patients developed nausea, fever, headache, muscle pain, and loss of appetite. It is important to recognize that the clinical presentation of $C$. gattii infection may be quite subtle. For example, patients 3 and 9 were asymptomatic while patient 6 experienced only a nonspecific cough $[22,24,114]$. The most common pathology observed in these patients was nodules of the lung in the form of cryptococcomas. Interestingly, patient 7 presented with pulmonary ground-glass opacities, a pattern that is quite distinct from circumscribed nodules and rarely observed in the clinic [25]. The specific pulmonary pathology for patient 4 was not reported [22]. Meanwhile, CNS pathology was documented in four patients: patient 1 had cerebral cryptococcomas and patients 5,7 , and 12 presented with meningitis $[22,25,114]$.

All 171 C. gattii cases from the BC Cryptococcal Working Group study were caused by C. gattii serotype B [21]. This finding is consistent with the fact that serotype B exists at a much higher frequency in the environment compared to serotype C. In fact, the identification of C. gattii serotype C in the environment had not been described prior to 1998 [50, 122]. It also appears that the C. gattii major genotype VGIIa is highly associated with human disease: $82 \%$ of the cases were VGIIa, while the others were VGIIb (9\%) and VGI (6\%) [21]. Similarly, 5 of the 12 case reports from the Pacific west coast were VGIIa, one was VGIIb, and another was VGI, while the rest were unspecified. Apart from place of residence or travel, the main risk factors associated with the development of $C$. gattii disease were smoking $(50 \%)$, oral steroid use $(30 \%)$, invasive cancer (24\%), and chronic lung disease (13\%). HIV infection $(4 \%)$ and receipt of an organ transplant $(3 \%)$ were considered less common risk factors for the development of C. gattii disease in this study population [21]. Examination of the case reports shows a similar pattern; 4 of the 12 cases had a current or past history of smoking, and 7 of the 12 patients suffered from chronic disease and/or cancer, had undergone recent surgery, or had been exposed to corticosteroids.

Thus far, the median incubation time of C. gattii on Vancouver Island has been estimated to be 6-7 months with a range from 2 to 11 months [123]. One exception is the relatively short incubation period of six weeks that was observed in the Danish tourist visiting Vancouver Island [103]. The potentially long time frame from exposure to symptoms may impede the diagnosis of C. gattii infection. It is likely that the clinical incubation period depends on several variables such as differences in host immunity and the intensity of C. gattii exposure.

\section{Microbiology}

Laboratory testing is essential to diagnose C. gattii infection and generally requires analysis of tissue or fluids from infected sites such as cerebrospinal fluid, bronchial washings, blood, and urine [12]. Light microscopy is an efficient method for the rapid diagnosis of cryptococcosis. For this technique, fluid samples are usually stained with India ink while tissue samples may be stained with hematoxylin and eosin (H\&E), mucicarmine, or other stains [12, 20, 91]. In both cases, cryptococcal cells appear round to oval in shape, surrounded by a wide capsule. Infrequently, one may visualize nonencapsulated cryptococci under the microscope [12]. In the laboratory, both C. neoformans and C. gattii readily grow as round cream-colored mucoid colonies on Sabouraud dextrose agar, a selective medium that is widely used for the isolation of yeast [12]. Alternatively, malt extract agar may be used to selectively isolate fungi [12, 47]. Differential microbial media such as Staib agar or birdseed agar may be used to distinguish dark brown colonies of $C$. neoformans or C. gattii from other fungi [47, 124]. Further differentiation of cryptococcal species can be accomplished on L-canavanine-glycine-bromthymol blue (CGB) agar; $C$. gattii colours the medium blue while $C$. neoformans does not (medium remains yellow) [125]. Though not required for clinical management, the fungus may be viewed in its sexual state by growing the cells on V8 medium in the dark followed by fixation and staining to visualize the hyphae, nuclei, and septa [101]. Finally, it is possible to determine the exact serotype of a cryptococcal isolate using a slide agglutination assay although commercial kits for this purpose are not currently available $[22,25]$.

In vitro activity of antifungal agents may be helpful in guiding the clinical management of severe cryptococcal infection including meningoencephalitis [126]. A slower clinical response of $C$. gattii to antifungal therapy has 
TABLE 2: Summary of case reports of C. gattii infection.

\begin{tabular}{|c|c|c|c|c|c|c|}
\hline & Age (sex) & Residence & Exposure & $\begin{array}{l}\text { Health } \\
\text { conditions }\end{array}$ & Symptoms & $\begin{array}{l}\text { Pathology } \\
\text { (molecular type) }\end{array}$ \\
\hline $1[22]$ & $47(\mathrm{M})$ & $\begin{array}{l}\text { BC mainland } \\
\text { (on coast north } \\
\text { of } \mathrm{VI} \text { ) }\end{array}$ & $\begin{array}{l}\text { Yard/landscaping } \\
\text { work at residence }\end{array}$ & $\begin{array}{l}\text { Chronic } \\
\text { hepatitis C, drug } \\
\text { addiction }\end{array}$ & $\begin{array}{l}\text { Cough, chills, night } \\
\text { sweats, nausea, } \\
\text { muscular pain, } \\
\text { headache, appetite } \\
\text { loss, stiff neck }\end{array}$ & $\begin{array}{l}\text { Lung/brain } \\
\text { nodules (VGI) }\end{array}$ \\
\hline $2[22]$ & $48(\mathrm{~F})$ & $\begin{array}{l}\text { BC (lower } \\
\text { mainland) }\end{array}$ & $\begin{array}{l}\text { Deforestation near } \\
\text { residence, yard } \\
\text { work, last visited } \\
\text { VI } 4 \text { years ago }\end{array}$ & None & $\begin{array}{l}\text { Dyspnea, fever, chills, } \\
\text { headache, night } \\
\text { sweats, appetite loss, } \\
\text { nausea, muscular } \\
\text { pain }\end{array}$ & Lung mass (VGIIa) \\
\hline $3[22]$ & $73(\mathrm{~F})$ & $\mathrm{BC}$ & $\begin{array}{l}\text { Little outdoor } \\
\text { exposure, last } \\
\text { visited VI } 14 \text { years } \\
\text { ago }\end{array}$ & $\begin{array}{l}\text { Chronic renal } \\
\text { failure, lung } \\
\text { disease, breast } \\
\text { cancer, hip } \\
\text { surgery }\end{array}$ & None & $\begin{array}{l}\text { Lung nodule } \\
\text { (VGIIa) }\end{array}$ \\
\hline $4[22]$ & $59(\mathrm{M})$ & OR & $\begin{array}{l}\text { No travel out of } \\
\text { OR in last year }\end{array}$ & $\begin{array}{l}\text { Scarred lung } \\
\text { tissue (due to } \\
\text { occupation) }\end{array}$ & $\begin{array}{l}\text { Cough, dyspnea, } \\
\text { fever, chills, nausea, } \\
\text { weight loss, muscular } \\
\text { pain }\end{array}$ & $\begin{array}{l}\text { Not specified } \\
\text { (VGIIa) }\end{array}$ \\
\hline $5[22]$ & $87(\mathrm{M})$ & OR & $\begin{array}{l}\text { Travel to parts of } \\
\text { OR, WA \& CO }\end{array}$ & $\begin{array}{l}\text { Chronic } \\
\text { lymphocytic } \\
\text { leukemia (oral } \\
\text { steroid) }\end{array}$ & $\begin{array}{l}\text { Fever, weight loss, } \\
\text { appetite loss }\end{array}$ & $\begin{array}{l}\text { Meningitis } \\
\text { (VGIIb) }\end{array}$ \\
\hline $6[24]$ & $74(\mathrm{M})$ & $\begin{array}{l}\text { WA (Puget } \\
\text { Sound) }\end{array}$ & $\begin{array}{l}\text { Travel to south CA } \\
\text { and } \mathrm{HI} \text { in last year }\end{array}$ & $\begin{array}{l}\text { Large granular } \\
\text { lymphocytic } \\
\text { leukemia } \\
\text { (steroid and } \\
\text { hormone) }\end{array}$ & Cough & $\begin{array}{l}\text { Lung nodule } \\
\text { (VGIIa) }\end{array}$ \\
\hline $7[25]$ & $45(\mathrm{~F})$ & Alberta & $\begin{array}{l}\text { Holidays spent on } \\
\text { southeast shore of } \\
\text { VI, park visits }\end{array}$ & None & $\begin{array}{l}\text { Headache, blurred } \\
\text { vision, } \\
\text { photosensitivity, } \\
\text { nausea, vomiting, } \\
\text { cough }\end{array}$ & $\begin{array}{l}\text { Lung opacities, } \\
\text { airspace disease, } \\
\text { meningitis (not } \\
\text { specified) }\end{array}$ \\
\hline $8[103]$ & $51(\mathrm{M})$ & Denmark & $\begin{array}{l}\text { Travel to Victoria } \\
\text { and VI east coast } \\
\text { for } 7 \text { days, garden } \\
\text { visits }\end{array}$ & $\begin{array}{l}\text { Psoriatic gout } \\
\text { (nonsteroidal } \\
\text { anti- } \\
\text { inflammatory } \\
\text { drug) }\end{array}$ & $\begin{array}{l}\text { Chest pain, fever, } \\
\text { cough, dyspnea }\end{array}$ & $\begin{array}{l}3 \text { large nodular } \\
\text { infiltrates (VGIIa) }\end{array}$ \\
\hline $9[114]$ & $54(\mathrm{M})$ & Not specified & Not specified & $\begin{array}{l}\text { Bradycardia, } \\
\text { acute } \\
\text { myocardial } \\
\text { infarction, } \\
\text { smoker }\end{array}$ & None & $\begin{array}{l}\text { Lung opacity (not } \\
\text { specified) }\end{array}$ \\
\hline $10[114]$ & $62(\mathrm{M})$ & Not specified & Not specified & Previous smoker & Chest pain & $\begin{array}{l}\text { Lung nodules (not } \\
\text { specified) }\end{array}$ \\
\hline $11[114]$ & $69(\mathrm{~F})$ & Not specified & $\begin{array}{l}\text { Exposure to } \\
\text { tuberculosis }\end{array}$ & $\begin{array}{l}\text { Previous } \\
\text { smoker, total } \\
\text { colectomy due } \\
\text { to ulcerative } \\
\text { colitis }\end{array}$ & Cough, dyspnea & $\begin{array}{l}\text { Cavitary lesion } \\
\text { (not specified) }\end{array}$ \\
\hline $12[114]$ & $65(\mathrm{M})$ & Not specified & $\begin{array}{l}\text { Occupational } \\
\text { (painter) }\end{array}$ & $\begin{array}{l}\text { Previous } \\
\text { smoker, mild } \\
\text { recurrent } \\
\text { hemoptysis }\end{array}$ & Not specified & $\begin{array}{l}\text { Lung opacity, } \\
\text { meningitis (not } \\
\text { specified) }\end{array}$ \\
\hline
\end{tabular}

Legend: BC: British Columbia, CA: California, CO: Colorado, HI: Hawaii, OR: Oregon, VI: Vancouver Island, WA: Washington. 
been attributed to serotype-specific differences in antifungal activity though there are no consistent or predictable data to support this hypothesis $[127,128]$. To evaluate this possibility further, a recently published study compared the susceptibility of 86 C. neoformans and 42 C. gattii isolates to various antifungal drugs including amphotericin $\mathrm{B}$, flucytosine, fluconazole, posaconazole, voriconazole, and isavuconazole [129]. The major finding was that all antifungal agents tested retained activity against all cryptococcal isolates with the newer azoles exhibiting greater potency compared to fluconazole and flucytosine. In this report, no significant differences in drug potency were observed for $C$. gattii serotypes B or C compared to other serotypes.

\section{Spread of the Vancouver Island C. gattii Outbreak}

The colonization of C. gattii on Vancouver Island, and possibly other adjacent regions, indicates that this fungus has the ability to adapt to new environmental conditions. It has been suggested by Kidd et al. that the temperate climate of Vancouver Island may provide a favorable niche for the survival and dispersal of C. gattii [23]. Global warming has also been proposed to favor C. gattii colonization of new geographic regions [23]. Studies in Colombia have also suggested a correlation between climate and distribution of cryptococcal serotypes A to C. Specifically, differential tolerance of climatic and possibly other environmental conditions by individual serotypes may affect their geographic and ecological distribution [37, 130]. The modes of dispersal of C. gattii have been studied on Vancouver Island. Some trees in the region show intermittent positivity, suggesting the movement of fungal spores [121]. High $C$. gattii levels exist in public areas such as park entrances, parking lots, and beaches despite the fact that these areas are characterized by low tree density $[47,121]$. A significant amount of C. gattii dispersal appears to be mediated by human activity, including contact with footwear and car wheel wells, deforestation, and gardening [121]. Avian and perhaps other animal migrations, as well as insect vectors such as beetles and caterpillars [15], may also contribute to dispersal [121].

Has C. gattii colonized other regions on the Pacific west coast? It is known that C. gattii (serotype C) was isolated from a eucalyptus tree in San Francisco in 1992, but since then C. gattii has not been found in that environment. In order to determine whether C. gattii has spread to the United States, Fraser et al. investigated possible colonization on the San Juan Islands, the closest U.S. region to Vancouver Island [131]. The San Juan Islands also exhibit a temperate climate zone that is similar, but not identical, to the CDF biogeoclimatic zone of Vancouver Island. Although other fungi of the phylum Basidiomycota, namely Cryptococcus laurentii and Cryptococcus cellulolyticus, were isolated, C. gattii was not detected. This suggests that $C$. gattii may not have yet colonized the San Juan Islands, or dispersal of the fungus is impeded by a geographical barrier that is the Juan de Fuca strait [131]. In a recent study by
MacDougall et al., C. gattii was isolated from environments outside of Vancouver Island including the British Columbia mainland, the Gulf islands, and Washington state, but no positive environmental samples were found in Oregon [22]. In the clinic, C. gattii has been isolated in Seattle (1975), Vancouver Island, and the British Columbia mainland, and most recently in Oregon, Washington, and Alberta [22$25,63]$.

\section{Conclusion}

The recent outbreak of $C$. gattii infection in the Pacific Northwest highlights the fact that this fungus is an important emerging pathogen that can adapt to new potential environmental niches. C. gattii isolates found on Vancouver Island appear to be hypervirulent, as the number of infected individuals per million people per year between 2002 and 2005 was more than 36 times higher on Vancouver Island compared to endemic regions such as Australia [22, 23]. It is in the interest of scientists and clinicians alike to better understand the pathogenesis of C. gattii disease in order to discover effective prevention and treatment strategies, including measures to limit human exposure to this pathogenic fungus. Employing C. neoformans as a model organism to understand the disease-causing potential of $C$. gattii is no longer sufficient since fundamental disparities such as differences in host tropism and the expression of certain virulence factors exist between the two species.

\section{Acknowledgments}

This work was supported in part by the Research Institute of the McGill University Health Centre, the Quebec Respiratory Health Training Program (SC), a Burroughs Wellcome Career Award in the Biomedical Sciences (SQ), and a Canada Research Chair (SQ).

\section{References}

[1] D. W. Warnock, "Mycology," in Manual of Clinical Microbiology. Vol. 2, P. R. Murray, E. J. Baron, J. H. Jorgensen, M. L. Landry, and M. A. Pfaller, Eds., ASM Press, Washington, DC, USA, 2007.

[2] D. L. Hawksworth, "The magnitude of fungal diversity: the 1.5 million species estimate revisited," Mycological Research, vol. 105, no. 12, pp. 1422-1432, 2001.

[3] K. A. Marr, R. A. Carter, F. Crippa, A. Wald, and L. Corey, "Epidemiology and outcome of mould infections in hematopoietic stem cell transplant recipients," Clinical Infectious Diseases, vol. 34, no. 7, pp. 909-917, 2002.

[4] S. Husain, B. D. Alexander, P. Munoz, et al., "Opportunistic mycelial fungal infections in organ transplant recipients: emerging importance of non-Aspergillus mycelial fungi," Clinical Infectious Diseases, vol. 37, no. 2, pp. 221-229, 2003.

[5] M. Chayakulkeeree and J. R. Perfect, "Cryptococcosis," Infectious Disease Clinics of North America, vol. 20, no. 3, pp. 507-544, 2006.

[6] T. Bicanic and T. S. Harrison, "Cryptococcal meningitis," British Medical Bulletin, vol. 72, no. 1, pp. 99-118, 2004. 
[7] F. Sanfelice, "Sull'azione patogena dei blastomiceti," Annali Istituto d'Igiene della Universitá di Roma, vol. 5, pp. 239-262, 1895.

[8] K. J. Kwon-Chung and J. E. Bennett, Medical Mycology, Lea and Febiger, Philadelphia, Pa, USA, 1992.

[9] L. Ajello, "Occurrence of Cryptococcus neoformans in soils," The American Journal of Hygiene, vol. 67, no. 1, pp. 72-77, 1958.

[10] C. W. Emmons, "Isolation of Cryptococcus neoformans from soil," The Journal of Bacteriology, vol. 62, no. 6, pp. 685-690, 1951.

[11] K. J. Kwon-Chung, "A new genus, Filobasidiella, the perfect state of Cryptococcus neoformans," Mycologia, vol. 67, no. 6, pp. 1197-1200, 1975.

[12] D. Ellis, "Mycology Online," 2007, http://www.mycology.adelaide.edu.au.

[13] J. R. Perfect and A. Casadevall, "Cryptococcosis," Infectious Disease Clinics of North America, vol. 16, no. 4, pp. 837-874, 2002.

[14] R. Vanbreuseghem and M. Takashio, "An atypical strain of Cryptococcus neoformans (San Felice) Vuillemin 1894. II. Cryptococcus neoformans var. gattii var. nov," Annales de la Societe Belge de Medecine Tropicale, vol. 50, no. 6, pp. 695$702,1970$.

[15] T. C. Sorrell, "Cryptococcus neoformans variety gattii," Medical Mycology, vol. 39, no. 2, pp. 155-168, 2001.

[16] K. J. Kwon-Chung and J. E. Bennett, "Epidemiologic differences between the two varieties of Cryptococcus neoformans," American Journal of Epidemiology, vol. 120, no. 1, pp. 123130, 1984.

[17] T. Boekhout, B. Theelen, M. Diaz, et al., "Hybrid genotypes in the pathogenic yeast Cryptococcus neoformans," Microbiology, vol. 147, no. 4, pp. 891-907, 2001.

[18] B. Speed and D. Dunt, "Clinical and host differences between infections with the two varieties of Cryptococcus neoformans," Clinical Infectious Diseases, vol. 21, no. 1, pp. 35-36, 1995.

[19] R. Rozenbaum and A. J. Gonçalves, "Clinical epidemiological study of 171 cases of cryptococcosis," Clinical Infectious Diseases, vol. 18, no. 3, pp. 369-380, 1994.

[20] L. M. N. Hoang, J. A. Maguire, P. Doyle, M. Fyfe, and D. L. Roscoe, "Cryptococcus neoformans infections at Vancouver Hospital and Health Sciences Centre (1997-2002): epidemiology, microbiology and histopathology," Journal of Medical Microbiology, vol. 53, no. 9, pp. 935-940, 2004.

[21] C. Berrie, "Outbreak of Cryptococcus gattii infection in humans in British Columbia," Medscape Medical News, 2007.

[22] L. MacDougall, S. E. Kidd, E. Galanis, et al., "Spread of Cryptococcus gattii in British Columbia, Canada, and detection in the Pacific Northwest, USA," Emerging Infectious Diseases, vol. 13, no. 1, pp. 42-50, 2007.

[23] S. E. Kidd, F. Hagen, R. L. Tscharke, et al., "A rare genotype of Cryptococcus gattii caused the cryptococcosis outbreak on Vancouver Island (British Columbia, Canada)," Proceedings of the National Academy of Sciences of the United States of America, vol. 101, no. 49, pp. 17258-17263, 2004.

[24] A. Upton, J. A. Fraser, S. E. Kidd, et al., "First contemporary case of human infection with Cryptococcus gattii in puget sound: evidence for spread of the Vancouver Island outbreak," Journal of Clinical Microbiology, vol. 45, no. 9, pp. 3086-3088, 2007.

[25] R. Levy, J. Pitout, P. Long, and M. J. Gill, "Late presentation of Cryptococcus gattii meningitis in a traveller to Vancouver Island: a case report," The Canadian Journal of Infectious
Diseases and Medical Microbiology, vol. 18, no. 3, pp. 197199, 2007.

[26] J. W. Fell, T. Boekhout, A. Fonseca, G. Scorzetti, and A. Statzell-Tallman, "Biodiversity and systematics of basidiomycetous yeasts as determined by large-subunit rDNA D1/D2 domain sequence analysis," International Journal of Systematic and Evolutionary Microbiology, vol. 50, no. 3, pp. 1351-1371, 2000.

[27] G. Scorzetti, J. W. Fell, A. Fonseca, and A. Statzell-Tallman, "Systematics of basidiomycetous yeasts: a comparison of large subunit D1/D2 and internal transcribed spacer rDNA regions," FEMS Yeast Research, vol. 2, no. 4, pp. 495-517, 2002.

[28] C. Duncan, C. Stephen, and J. Campbell, "Clinical characteristics and predictors of mortality for Cryptococcus gattii infection in dogs and cats of southwestern British Columbia," Canadian Veterinary Journal, vol. 47, no. 10, pp. 993-998, 2006.

[29] K. J. Kwon-Chung and A. Varma, "Do major species concepts support one, two or more species within Cryptococcus neoformans?" FEMS Yeast Research, vol. 6, no. 4, pp. 574-587, 2006.

[30] E. E. Evans, "The antigenic composition of Cryptococcus neoformans. I. A serologic classification by means of the capsular and agglutination reactions," The Journal of Immunology, vol. 64, no. 5, pp. 423-430, 1950.

[31] L. E. Yauch, J. S. Lam, and S. M. Levitz, "Direct inhibition of T-cell responses by the Cryptococcus capsular polysaccharide glucuronoxylomannan," PLoS Pathogens, vol. 2, no. 11, pp. 1060-1068, 2006.

[32] D. E. Wilson, J. E. Bennett, and J. W. Bailey, "Serologic grouping of Cryptococcus neoformans," Proceedings of the Society for Experimental Biology and Medicine, vol. 127, no. 3, pp. 820-823, 1968.

[33] K. B. Lengeler, G. M. Cox, and J. Heitman, "Serotype AD strains of Cryptococcus neoformans are diploid or aneuploid and are heterozygous at the mating-type locus," Infection and Immunity, vol. 69, no. 1, pp. 115-122, 2001.

[34] S. K. Mishra, F. Staib, U. Folkens, and R. A. Fromtling, "Serotypes of Cryptococcus neoformans strains isolated in Germany," Journal of Clinical Microbiology, vol. 14, no. 1, pp. 106-107, 1981.

[35] M. Bovers, F. Hagen, E. E. Kuramae, et al., "Unique hybrids between the fungal pathogens Cryptococcus neoformans and Cryptococcus gattii," FEMS Yeast Research, vol. 6, no. 4, pp. 599-607, 2006.

[36] M. Bovers, F. Hagen, E. E. Kuramae, et al., "AIDS patient death caused by novel Cryptococcus neoformans $\times$ C. gattii hybrid," Emerging Infectious Diseases, vol. 14, no. 7, pp. 11051108, 2008.

[37] M. Rovers, F. Hagen, and T. Boekhout, "Diversity of the Cryptococcus neoformans-Cryptococcus gattii species complex," Revista Iberoamericana de Micologia, vol. 25, no. 1, pp. S4-S12, 2008.

[38] K. J. Kwon-Chung, T. Boekhout, J. W. Fell, and M. Diaz, "Proposal to conserve the name Cryptococcus gattii against C. hondurianus and C. bacillisporus (Basidiomycota, Hymenomycetes, Tremellomycetidae)," Taxon, vol. 51, no. 4, pp. 804806, 2002.

[39] J. Xu, R. Vilgalys, and T. G. Mitchell, "Multiple gene genealogies reveal recent dispersion and hybridization in the human pathogenic fungus Cryptococcus neoformans," Molecular Ecology, vol. 9, no. 10, pp. 1471-1481, 2000. 
[40] K. J. Kwon-Chung, J. E. Bennett, and J. C. Rhodes, "Taxonomic studies on Filobasidiella species and their anamorphs," Antonie van Leeuwenhoek, vol. 48, no. 1, pp. 25-38, 1982.

[41] K. J. Kwon-Chung, "A new species of Filobasidiella, the sexual state of Cryptococcus neoformans B and C serotypes," Mycologia, vol. 68, no. 4, pp. 943-946, 1976.

[42] W. Meyer, K. Marszewska, M. Amirmostofian, et al., "Molecular typing of global isolates of Cryptococcus neoformans var. neoformans by polymerase chain reaction fingerprinting and randomly amplified polymorphic DNA—a pilot study to standardize techniques on which to base a detailed epidemiological survey," Electrophoresis, vol. 20, no. 8, pp. 1790-1799, 1999.

[43] W. Meyer, T. G. Mitchell, E. Z. Freedman, and R. Vilgalys, "Hybridization probes for conventional DNA fingerprinting used as single primers in the polymerase chain reaction to distinguish strains of Cryptococcus neoformans," Journal of Clinical Microbiology, vol. 31, no. 9, pp. 2274-2280, 1993.

[44] W. Meyer, A. Castañeda, S. Jackson, et al., "Molecular typing of IberoAmerican Cryptococcus neoformans isolates," Emerging Infectious Diseases, vol. 9, no. 2, pp. 189-195, 2003.

[45] M. Bovers, F. Hagen, E. E. Kuramae, and T. Boekhout, "Six monophyletic lineages identified within Cryptococcus neoformans and Cryptococcus gattii by multi-locus sequence typing," Fungal Genetics and Biology, vol. 45, no. 4, pp. 400421, 2008.

[46] S. E. Kidd, H. Guo, K. H. Bartlett, J. Xu, and J. W. Kronstad, "Comparative gene genealogies indicate that two clonal lineages of Cryptococcus gattii in British Columbia resemble strains from other geographical areas," Eukaryotic Cell, vol. 4, no. 10, pp. 1629-1638, 2005.

[47] S. E. Kidd, Y. Chow, S. Mak, et al., "Characterization of environmental sources of the human and animal pathogen Cryptococcus gattii in British Columbia, Canada, and the Pacific Northwest of the United States," Applied and Environmental Microbiology, vol. 73, no. 5, pp. 1433-1443, 2007.

[48] T. J. Pfeiffer and D. H. Ellis, "Environmental isolation of Cryptococcus neoformans var. gattii from Eucalyptus tereticornis," Journal of Medical and Veterinary Mycology, vol. 30, no. 5, pp. 407-408, 1992.

[49] D. H. Ellis and T. J. Pfeiffer, "Natural habitat of Cryptococcus neoformans var. gattii," Journal of Clinical Microbiology, vol. 28, no. 7, pp. 1642-1644, 1990.

[50] S. E. Kidd, T. C. Sorrell, and W. Meyer, "Isolation of two molecular types of Cryptococcus neoformans var. gattii from insect frass," Medical Mycology, vol. 41, no. 2, pp. 171-176, 2003.

[51] E. Gezuele, L. Calegari, D. Sanabría, G. Davel, and E. Civila, "Isolation in uruguay of Cryptococcus neoformans var. gattii from nest of the wasp Polybia occidentalis," Revista Iberoamericana de Micología, vol. 10, no. 1, pp. 5-6, 1993.

[52] J. P. van der Walt and D. B. Scott, "Bullera dendrophila sp. n," Antonie van Leeuwenhoek, vol. 36, no. 1, pp. 383-387, 1970.

[53] J. P. van der Walt, D. B. Scott, and W. C. van der Klift, "Six new Candida species from South African insect sources," Mycopathologia et Mycologia Applicata, vol. 47, no. 3, pp. 221-236, 1972.

[54] J. P. van der Walt, Y. Yamada, N. P. Ferreira, and P. D. G. Richards, "New basidiomycetous yeasts from Southern Africa. II. Sterigmatomyces wingfieldii sp. n," Antonie van Leeuwenhoek, vol. 53, no. 3, pp. 137-142, 1987.

[55] D. Ellis, D. Marriott, R. A. Hajjeh, D. Warnock, W. Meyer, and R. Barton, "Epidemiology: surveillance of fungal infections," Medical Mycology, vol. 38, supplement 1, pp. 173-182, 2000.
[56] K. Tintelnot, K. Lemmer, H. Losert, G. Schär, and A. Polak, "Follow-up of epidemiological data of cryptococcosis in Austria, Germany and Switzerland with special focus on the characterization of clinical isolates," Mycoses, vol. 47, no. 1112, pp. 455-464, 2004.

[57] M. Katsu, S. Kidd, A. Ando, et al., "The internal transcribed spacers and 5.8S rRNA gene show extensive diversity among isolates of the Cryptococcus neoformans species complex," FEMS Yeast Research, vol. 4, no. 4-5, pp. 377-388, 2004.

[58] T. C. Sorrell, S. C. A. Chen, P. Ruma, et al., "Concordance of clinical and environmental isolates of Cryptococcus neoformans var. gattii by random amplification of polymorphic DNA analysis and PCR fingerprinting," Journal of Clinical Microbiology, vol. 34, no. 5, pp. 1253-1260, 1996.

[59] M. A. Viviani, M. Cogliati, M. C. Esposto, et al., "Molecular analysis of 311 Cryptococcus neoformans isolates from a 30month ECMM survey of cryptococcosis in Europe," FEMS Yeast Research, vol. 6, no. 4, pp. 614-619, 2006.

[60] A. Jenney, K. Pandithage, D. A. Fisher, and B. J. Currie, "Cryptococcus infection in tropical Australia," Journal of Clinical Microbiology, vol. 42, no. 8, pp. 3865-3868, 2004.

[61] L. T. Campbell, B. J. Currie, M. Krockenberger, et al., "Clonality and recombination in genetically differentiated subgroups of Cryptococcus gattii," Eukaryotic Cell, vol. 4, no. 8, pp. 1403-1409, 2005.

[62] S. C. A. Chen, B. J. Currie, H. M. Campbell, et al., "Cryptococcus neoformans var. gattii infection in northern Australia: existence of an environmental source other than known host eucalypts," Transactions of the Royal Society of Tropical Medicine and Hygiene, vol. 91, no. 5, pp. 547-550, 1997.

[63] J. A. Fraser, S. S. Giles, E. C. Wenink, et al., "Same-sex mating and the origin of the Vancouver Island Cryptococcus gattii outbreak," Nature, vol. 437, no. 7063, pp. 1360-1364, 2005.

[64] P. Escandón, A. Sánchez, M. Martínez, W. Meyer, and E. Castañeda, "Molecular epidemiology of clinical and environmental isolates of the Cryptococcus neoformans species complex reveals a high genetic diversity and the presence of the molecular type VGII mating type a in Colombia," FEMS Yeast Research, vol. 6, no. 4, pp. 625-635, 2006.

[65] L. Trilles, M. D. S. Lazéra, B. Wanke, et al., "Regional pattern of the molecular types of Cryptococcus neoformans and Cryptococcus gattii in Brazil," Memórias do Instituto Oswaldo Cruz, vol. 103, no. 5, pp. 455-462, 2008.

[66] J. A. Fraser, R. L. Subaran, C. B. Nichols, and J. Heitman, "Recapitulation of the sexual cycle of the primary fungal pathogen Cryptococcus neoformans var. gattii: implications for an outbreak on Vancouver Island, Canada," Eukaryotic Cell, vol. 2, no. 5, pp. 1036-1045, 2003.

[67] T. R. Kozel and R. P. Mastroianni, "Inhibition of phagocytosis by cryptococcal polysaccharide: dissociation of the attachment and ingestion phases of phagocytosis," Infection and Immunity, vol. 14, no. 1, pp. 62-67, 1976.

[68] H. L. Collins and G. J. Bancroft, "Encapsulation of Cryptococcus neoformans impairs antigen-specific T-cell responses," Infection and Immunity, vol. 59, no. 11, pp. 3883-3888, 1991.

[69] A. Vecchiarelli, C. Retini, D. Pietrella, et al., "Downregulation by cryptococcal polysaccharide of tumor necrosis factor alpha and interleukin- $1 \beta$ secretion from human monocytes," Infection and Immunity, vol. 63, no. 8, pp. 2919-2923, 1995.

[70] J. W. Murphy and J. W. Moorhead, "Regulation of cellmediated immunity in cryptococcosis. I. Induction of specific afferent $\mathrm{T}$ suppressor cells by cryptococcal antigen," The Journal of Immunology, vol. 128, no. 1, pp. 276-283, 1982. 
[71] Z. M. Dong, L. Jackson, and J. W. Murphy, "Mechanisms for induction of L-selectin loss from $\mathrm{T}$ lymphocytes by a cryptococcal polysaccharide, glucuronoxylomannan," Infection and Immunity, vol. 67, no. 1, pp. 220-229, 1999.

[72] Y. Wang and A. Casadevall, "Decreased susceptibility of melanized Cryptococcus neoformans to UV light," Applied and Environmental Microbiology, vol. 60, no. 10, pp. 3864-3866, 1994.

[73] Y. Wang, P. Aisen, and A. Casadevall, "Cryptococcus neoformans melanin and virulence: mechanism of action," Infection and Immunity, vol. 63, no. 8, pp. 3131-3136, 1995.

[74] E. S. Jacobson and H. S. Emery, "Catecholamine uptake, melanization, and oxygen toxicity in Cryptococcus neoformans," Journal of Bacteriology, vol. 173, no. 1, pp. 401-403, 1991.

[75] J. D. Nosanchuk and A. Casadevall, "Cellular charge of Cryptococcus neoformans: contributions from the capsular polysaccharide, melanin, and monoclonal antibody binding," Infection and Immunity, vol. 65, no. 5, pp. 1836-1841, 1997.

[76] G. M. Megson, D. A. Stevens, J. R. Hamilton, and D. W. Denning, "D-mannitol in cerebrospinal fluid of patients with AIDS and cryptococcal meningitis," Journal of Clinical Microbiology, vol. 34, no. 1, pp. 218-221, 1996.

[77] A. Casadevall and J. R. Perfect, Cryptococcus neoformans, American Society for Microbiology Press, Washington, DC, USA, 1998.

[78] V. Chaturvedi, B. Wong, and S. L. Newman, "Oxidative killing of Cryptococcus neoformans by human neutrophils: evidence that fungal mannitol protects by scavenging reactive oxygen intermediates," The Journal of Immunology, vol. 156, no. 10, pp. 3836-3840, 1996.

[79] L.-C. Chen, E. S. Blank, and A. Casadevall, "Extracellular proteinase activity of Cryptococcus neoformans," Clinical and Diagnostic Laboratory Immunology, vol. 3, no. 5, pp. 570-574, 1996.

[80] C. H. Brueske, "Proteolytic activity of a clinical isolate of Cryptococcus neoformans," Journal of Clinical Microbiology, vol. 23 , no. 3, pp. 631-633, 1986.

[81] H. E. Müller and K. K. Sethi, "Proteolytic activity of Cryptococcus neoformans against human plasma proteins," Medical Microbiology and Immunology, vol. 158, no. 2, pp. 129-134, 1972.

[82] P. Ruma-Haynes, A. G. Brownlee, and T. C. Sorrell, "A rapid method for detecting extracellular proteinase activity in Cryptococcus neoformans and a survey of 63 isolates," Journal of Medical Microbiology, vol. 49, no. 8, pp. 733-737, 2000.

[83] P. R. Williamson, "Biochemical and molecular characterization of the diphenol oxidase of Cryptococcus neoformans: identification as a laccase," Journal of Bacteriology, vol. 176, no. 3, pp. 656-664, 1994.

[84] C. E. Shaw and L. Kapica, "Production of diagnostic pigment by phenoloxidase activity of Cryptococcus neoformans," Applied Microbiology, vol. 24, no. 5, pp. 824-830, 1972.

[85] S. D. Narasipura, V. Chaturvedi, and S. Chaturvedi, "Characterization of Cryptococcus neoformans variety gattii SOD2 reveals distinct roles of the two superoxide dismutases in fungal biology and virulence," Molecular Microbiology, vol. 55, no. 6, pp. 1782-1800, 2005.

[86] S. C. A. Chen, L. C. Wright, J. C. Golding, and T. C. Sorrell, "Purification and characterization of secretory phospholipase B, lysophospholipase and lysophospholipase/transacylase from a virulent strain of the pathogenic fungus Cryptococcus neoformans," Biochemical Journal, vol. 347 , no. 2, pp. 431-439, 2000.
[87] G. M. Cox, J. Mukherjee, G. T. Cole, A. Casadevall, and J. R. Perfect, "Urease as a virulence factor in experimental cryptococcosis," Infection and Immunity, vol. 68, no. 2, pp. 443-448, 2000.

[88] M. A. Olszewski, M. C. Noverr, G.-H. Chen, et al., "Urease expression by Cryptococcus neoformans promotes microvascular sequestration, thereby enhancing central nervous system invasion," The American Journal of Pathology, vol. 164, no. 5, pp. 1761-1771, 2004.

[89] B. L. Wickes, U. Edman, and J. C. Edman, "The Cryptococcus neoformans STE12 $\alpha$ gene: a putative Saccharomyces cerevisiae STE12 homologue that is mating type specific," Molecular Microbiology, vol. 26, no. 5, pp. 951-960, 1997.

[90] C. L. Halliday, T. Bui, M. Krockenberger, R. Malik, D. H. Ellis, and D. A. Carter, "Presence of $\alpha$ and a mating types in environmental and clinical collections of Cryptococcus neoformans var. gattii strains from Australia," Journal of Clinical Microbiology, vol. 37, no. 9, pp. 2920-2926, 1999.

[91] N. Jain, L. Li, D. C. McFadden, et al., "Phenotypic switching in a Cryptococcus neoformans variety gattii strain is associated with changes in virulence and promotes dissemination to the central nervous system," Infection and Immunity, vol. 74, no. 2, pp. 896-903, 2006.

[92] P. M. Ellerbroek, A. M. E. Walenkamp, A. I. M. Hoepelman, and F. E. J. Coenjaerts, "Effects of the capsular polysaccharides of Cryptococcus neoformans on phagocyte migration and inflammatory mediators," Current Medicinal Chemistry, vol. 11, no. 2, pp. 253-266, 2004.

[93] Y. C. Chang, B. L. Wickes, G. F. Miller, L. A. Penoyer, and K. J. Kwon-Chung, "Cryptococcus neoformans STE12 $\alpha$ regulates virulence but is not essential for mating," Journal of Experimental Medicine, vol. 191, no. 5, pp. 871-882, 2000.

[94] R. Cherniak and J. B. Sundstrom, "Polysaccharide antigens of the capsule of Cryptococcus neoformans," Infection and Immunity, vol. 62, no. 5, pp. 1507-1512, 1994.

[95] P. Lupo, Y. C. Chang, B. L. Kelsall, et al., "The presence of capsule in Cryptococcus neoformans influences the gene expression profile in dendritic cells during interaction with the fungus," Infection and Immunity, vol. 76, no. 4, pp. 15811589, 2008.

[96] B. J. Young and T. R. Kozel, "Effects of strain variation, serotype, and structural modification on kinetics for activation and binding of C3 to Cryptococcus neoformans," Infection and Immunity, vol. 61, no. 7, pp. 2966-2972, 1993.

[97] D. H. Mitchell, T. C. Sorrell, A. M. Allworth, et al., "Cryptococcal disease of the CNS in immunocompetent hosts: influence of cryptococcal variety on clinical manifestations and outcome," Clinical Infectious Diseases, vol. 20, no. 3, pp. 611-616, 1995

[98] J. M. Torres-Rodríguez, E. Alvarado-Ramírez, and R. Gutiérrez-Gallego, "Urease activity in Cryptococcus neoformans and Cryptococcus gattii," Revista Iberoamericana de Micologia, vol. 25, no. 1, pp. 27-31, 2008.

[99] O. W. Liu, C. D. Chun, E. D. Chow, C. Chen, H. D. Madhani, and S. M. Noble, "Systematic genetic analysis of virulence in the human fungal pathogen Cryptococcus neoformans," Cell, vol. 135, no. 1, pp. 174-188, 2008.

[100] D. L. Goldman, B. C. Fries, S. P. Franzot, L. Montella, and A. Casadevall, "Phenotypic switching in the human pathogenic fungus Cryptococcus neoformans is associated with changes in virulence and pulmonary inflammatory response in rodents," Proceedings of the National Academy of Sciences of the United States of America, vol. 95, no. 25, pp. 14967-14972, 1998. 
[101] X. Lin, C. M. Hull, and J. Heitman, "Sexual reproduction between partners of the same mating type in Cryptococcus neoformans," Nature, vol. 434, no. 7036, pp. 1017-1021, 2005.

[102] C. M. Hull and J. Heitman, "Genetics of Cryptococcus neoformans," Annual Review of Genetics, vol. 36, pp. 557-615, 2002.

[103] J. Lindberg, F. Hagen, A. Laursen, J. Stenderup, and T. Boekhout, "Cryptococcus gattii risk for tourists visiting Vancouver Island, Canada," Emerging Infectious Diseases, vol. 13, no. 1, pp. 178-179, 2007.

[104] A. Torda, R. K. Kumar, and P. D. Jones, "The pathology of human and murine pulmonary infection with Cryptococcus neoformans var. gattii," Pathology, vol. 33, no. 4, pp. 475-478, 2001.

[105] J. Capilla, C. M. L. Maffei, K. V. Clemons, R. A. Sobel, and D. A. Stevens, "Experimental systemic infection with Cryptococcus neoformans var. grubii and Cryptococcus gattii in normal and immunodeficient mice," Medical Mycology, vol. 44, no. 7, pp. 601-610, 2006.

[106] T. Boekhout, A. van Belkum, A. C. A. P. Leenders, et al., "Molecular typing of Cryptococcus neoformans: taxonomic and epidemiological aspects," International Journal of Systematic Bacteriology, vol. 47, no. 2, pp. 432-442, 1997.

[107] J. M. Torres-Rodríguez, Y. Morera, T. Baró, J. M. Corominas, and E. Castañeda, "Pathogenicity of Cryptococcus neoformans var. gattii in an immunocompetent mouse model," Medical Mycology, vol. 41, no. 1, pp. 59-63, 2003.

[108] J. M. Dora, S. Kelbert, C. Deutschendorf, et al., "Cutaneous cryptococccosis due to Cryptococcus gattii in immunocompetent hosts: case report and review," Mycopathologia, vol. 161, no. 4, pp. 235-238, 2006.

[109] C. Duncan, H. Schwantje, C. Stephen, J. Campbell, and K. Bartlett, "Cryptococcus gattii in wildlife of Vancouver Island, British Columbia, Canada," Journal of Wildlife Diseases, vol. 42, no. 1, pp. 175-178, 2006.

[110] C. Stephen, S. Lester, W. Black, M. Fyfe, and S. Raverty, "Multispecies outbreak of cryptococcosis on southern Vancouver Island, British Columbia," The Canadian Veterinary Journal, vol. 43, no. 10, pp. 792-794, 2002.

[111] C. Duncan, C. Stephen, S. Lester, and K. H. Bartlett, "Subclinical infection and asymptomatic carriage of Cryptococcus gattii in dogs and cats during an outbreak of cryptococcosis," Medical Mycology, vol. 43, no. 6, pp. 511-516, 2005.

[112] T. F. Raso, K. Werther, E. T. Miranda, and M. J. S. MendesGiannini, "Cryptococcosis outbreak in psittacine birds in Brazil,” Medical Mycology, vol. 42, no. 4, pp. 355-362, 2004.

[113] M. B. Krockenberger, P. J. Canfield, and R. Malik, "Cryptococcus neoformans var. gattii in the koala (Phascolarctos cinereus): a review of 43 cases of cryptococcosis," Medical Mycology, vol. 41, no. 3, pp. 225-234, 2003.

[114] G. J. Dewar and J. K. Kelly, "Cryptococcus gattii: an emerging cause of pulmonary nodules," Canadian Respiratory Journal, vol. 15, no. 3, pp. 153-158, 2008.

[115] C. Duncan, C. Stephen, S. Lester, and K. H. Bartlett, "Followup study of dogs and cats with asymptomatic Cryptococcus gattii infection or nasal colonization," Medical Mycology, vol. 43, no. 7, pp. 663-666, 2005.

[116] C. Duncan, The emergence of Cryptococcus gattii in British Columbia: veterinary aspects, M.S. thesis, University of Saskatchewan, Saskatoon, Canada, 2005.

[117] J. D. Nosanchuk, S. Shoham, B. C. Fries, D. S. Shapiro, S. M. Levitz, and A. Casadevall, "Evidence of zoonotic transmission of Cryptococcus neoformans from a pet cockatoo to an immunocompromised patient," Annals of Internal Medicine, vol. 132, no. 3, pp. 205-208, 2000.

[118] K. Lagrou, J. van Eldere, S. Keuleers, et al., "Zoonotic transmission of Cryptococcus neoformans from a magpie to an immunocompetent patient," Journal of Internal Medicine, vol. 257, no. 4, pp. 385-388, 2005.

[119] C.-Y. Wang, H.-D. Wu, and P.-R. Hsueh, "Nosocomial transmission of cryptococcosis," The New England Journal of Medicine, vol. 352, no. 12, pp. 1271-1272, 2005.

[120] T. Baró, J. M. Torres-Rodríguez, M. H. De Mendoza, Y. Morera, and C. Alía, "First identification of autochthonous Cryptococcus neoformans var. gattii isolated from goats with predominantly severe pulmonary disease in Spain," Journal of Clinical Microbiology, vol. 36, no. 2, pp. 458-461, 1998.

[121] S. E. Kidd, P. J. Bach, A. O. Hingston, et al., "Cryptococcus gattii dispersal mechanisms, British Columbia, Canada," Emerging Infectious Diseases, vol. 13, no. 1, pp. 51-57, 2007.

[122] A. Callejas, N. Ordoñez, M. C. Rodriguez, and E. Castañeda, "First isolation of Cryptococcus neoformans var. gattii, serotype C, from the environment in Colombia," Medical Mycology, vol. 36, no. 5, pp. 341-344, 1998.

[123] L. MacDougall and M. Fyfe, "Emergence of Cryptococcus gattii in a novel environment provides clues to its incubation period," Journal of Clinical Microbiology, vol. 44, no. 5, pp. 1851-1852, 2006.

[124] F. Staib, M. Seibold, E. Antweiler, B. Fröhlich, S. Weber, and A. Blisse, "The brown colour effect (BCE) of Cryptococcus neoformans in the diagnosis, control and epidemiology of C. neoformans infections in AIDS patients," Zentralblatt für Bakteriologie Mikrobiologie und Hygiene A, vol. 266, no. 1-2, pp. 167-177, 1987.

[125] K. J. Kwon-Chung, I. Polacheck, and J. E. Bennett, "Improved diagnostic medium for separation of Cryptococcus neoformans var. neoformans (Serotypes A and D) and Cryptococcus neoformans var. gattii (serotypes B and C)," Journal of Clinical Microbiology, vol. 15, no. 3, pp. 535-537, 1982.

[126] M. S. Saag, R. J. Graybill, R. A. Larsen, et al., "Practice guidelines for the management of cryptococcal disease," Clinical Infectious Diseases, vol. 30, no. 4, pp. 710-718, 2000.

[127] A. Gomez-Lopez, O. Zaragoza, M. Dos Anjos Martins, M. C. Melhem, J. L. Rodriguez-Tudela, and M. Cuenca-Estrella, "In vitro susceptibility of Cryptococcus gattii clinical isolates," Clinical Microbiology and Infection, vol. 14, no. 7, pp. 727730, 2008.

[128] J. Morgan, K. M. McCarthy, S. Gould, et al., "Cryptococcus gattii infection: characteristics and epidemiology of cases identified in a South African province with high HIV seroprevalence, 2002-2004," Clinical Infectious Diseases, vol. 43, no. 8, pp. 1077-1080, 2006.

[129] G. R. Thompson III, N. P. Wiederhold, A. W. Fothergill, A. C. Vallor, B. L. Wickes, and T. F. Patterson, "Antifungal susceptibilities among different serotypes of Cryptococcus gattii and Cryptococcus neoformans," Antimicrobial Agents and Chemotherapy, vol. 53, no. 1, pp. 309-311, 2009.

[130] D. P. Granados and E. Castañeda, "Influence of climatic conditions on the isolation of members of the Cryptococcus neoformans species complex from trees in Colombia from 1992-2004," FEMS Yeast Research, vol. 6, no. 4, pp. 636-644, 2006.

[131] J. A. Fraser, S. M. Lim, S. Diezmann, et al., "Yeast diversity sampling on the San Juan Islands reveals no evidence for the spread of the Vancouver Island Cryptococcus gattii outbreak to this locale," FEMS Yeast Research, vol. 6, no. 4, pp. 620624, 2006. 


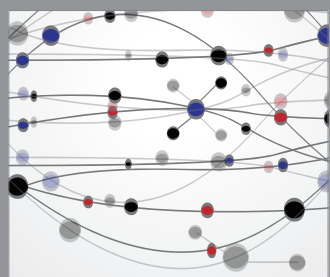

The Scientific World Journal
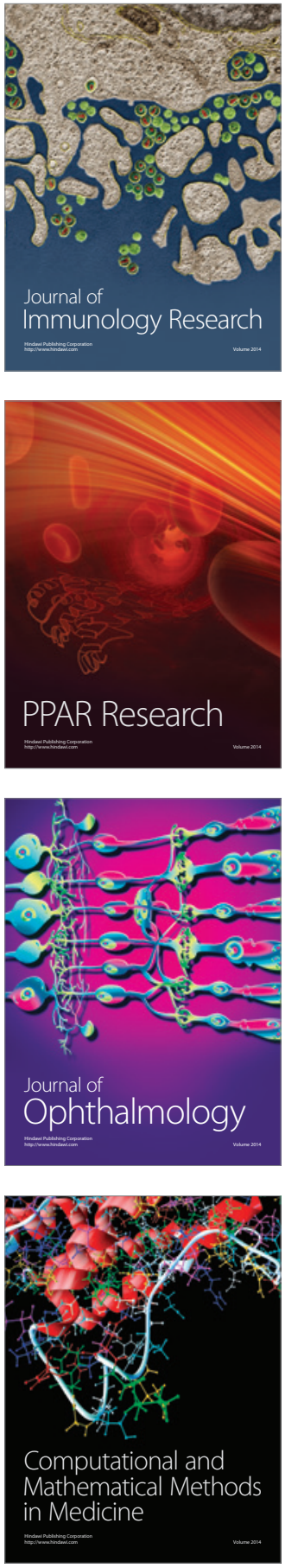

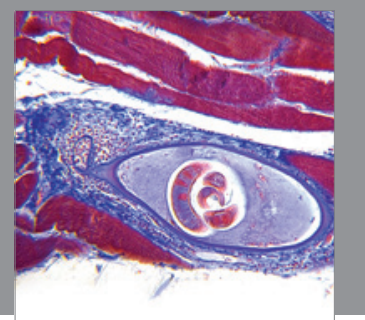

Gastroenterology

Research and Practice
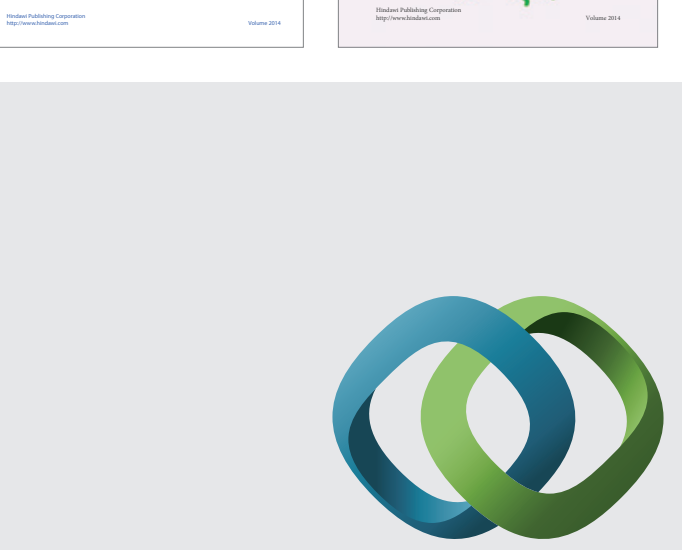

\section{Hindawi}

Submit your manuscripts at

http://www.hindawi.com
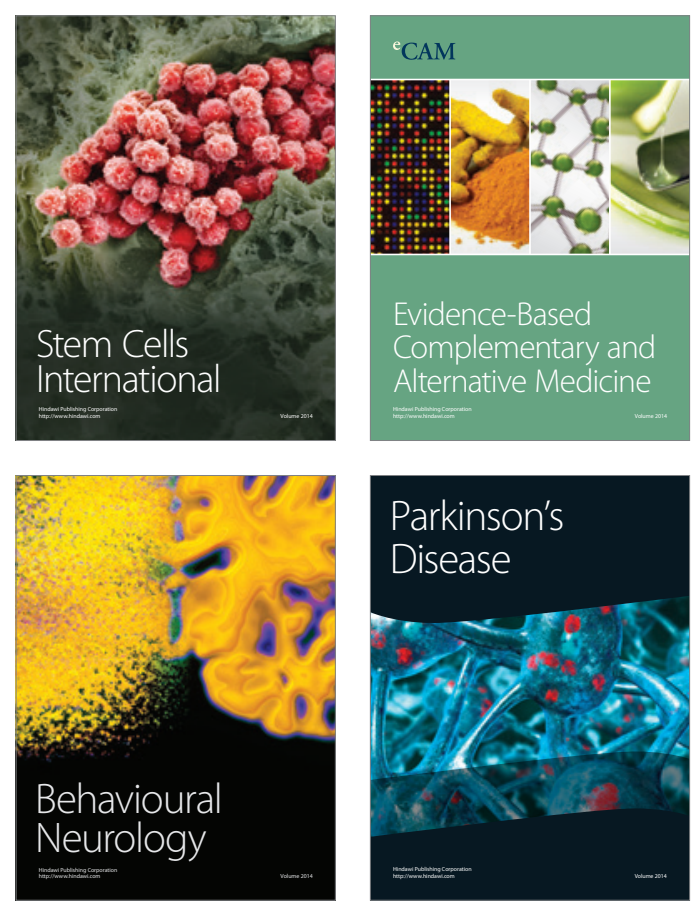

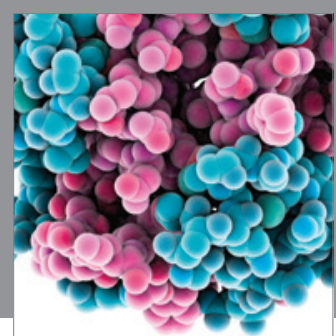

Journal of
Diabetes Research

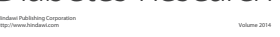

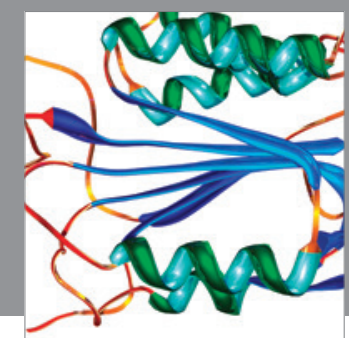

Disease Markers
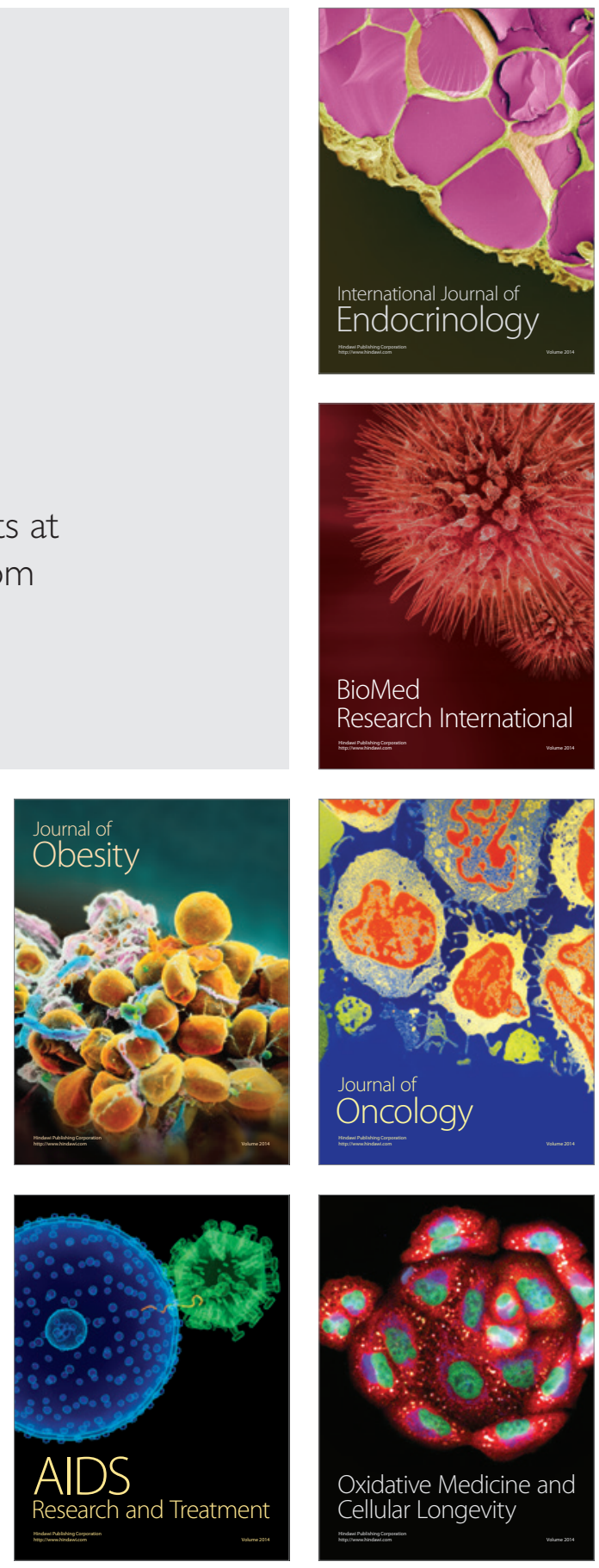